\title{
Analysis of existing methods of distribution of fuel costs in the combined generation of electric and thermal energy
}

\author{
Evgeny Boiko ${ }^{1}$, and Aleksandr Strashnikov, ${ }^{1, *}$ \\ ${ }^{1}$ Siberian Federal University, Krasnoyarsk, Russian Federation
}

\begin{abstract}
The analysis of the data obtained both according to the official, approved by the regulatory documents of the current legislation of the Russian Federation, methods of fuel separation in the combined generation of electric and thermal energy at CHPP and known alternative methods is carried out. It is shown that all methods have significant disadvantages in their application and need to be replaced by the only one method that will be a compromise for the entire professional community. The target area of the distribution of specific indicators for the desired only one method is identified and justified.
\end{abstract}

\section{Introduction}

The priority of combined generation of electric and thermal energy in power plants is a generally accepted principle. This allows us to solve the problems of increasing energy and environmental efficiency, reducing specific fuel costs, cost and tariffs [1,2]. One of the components of the solution of this problem is an objective assessment of the technical and economic attractiveness of generating enterprises that provide combined heat and electricity generation in terms of a scientifically based distribution of fuel costs. In this setting, the availability of an adequate method for calculating the specific performance indicators of power generating plants can be an effective tool for the development of the industry [3]. Among the main requirements that must be presented to this method are: ensuring a reduction in specific fuel consumption and, as a result, a reduction in physical fuel consumption; creating conditions of investment attractiveness for the modernization, reconstruction of existing and construction of new energy-efficient power plants; compliance with the economic interests of all participants (generating companies, consumers of electric and thermal energy, regulatory authorities, etc.).

It is known that fuel costs account for up to $2 / 3$ of energy production. Accordingly, the use of various wellknown methods of separating fuel costs between the generated electric and thermal energy is a fundamental factor affecting the formation of tariffs for consumers [4]. This situation is further aggravated by the fact that there is an objective contradiction in the understanding of the cost-effective tariff for various groups of consumers (industrial enterprises, the population, etc.), as well as generating companies, for which it is extremely important to be competitive both in the heat market (competition with boiler houses) and in the market of electric energy and capacity (competition with nuclear, hydroelectric and condensing power plants). Taking into account the above, in order to solve the problem of developing a generating company specializing in the combined generation of electric and thermal energy, it is important to create rules for setting tariffs for a long-term period [3].

\section{Overview of methods}

In the Russian Federation, the main accepted official method is the physical method. On the basis of the physical method, the method of tariff formation for thermal energy "Alternative boiler house" is developed. The specified methodology is fixed by the normative documents of the current legislation.

The presence of significant disadvantages of the physical method, the main of which is the principle of qualitative equality of the electric and thermal energy produced at the CHPP [5-10], has led to the development of a number of alternative methods, which are based on both thermodynamic principles of combined production of both types of energy, based on the first and second laws of thermodynamics, and economic, the essence of which is reduced to the difference in approaches to the distribution of the total amount of fuel consumed in combined production between the generated electric and thermal energy $[5,7,8,10]$.

The most well-known and well-studied method is the exergetic method for estimating specific characteristics, but, despite the presence of obvious advantages over the physical method, it has not received practical application [5-10]. In the works [5,7-9] a number of disadvantages of the exergetic method are indicated, one of which is that an increase in the specific fuel consumption for electricity of the CHPP will undermine the development of heat generation in Russia, as one of the main directions of heat power engineering [7].

In Europe and the United States, the Wagner method (equivalent condensing power plant) is adopted, which uses as a base value the specific fuel consumption for generating electric energy by steam turbine units of the 
condensation type. The introduction of this method has led to the development of heating and the overall increase in energy efficiency in these countries [10-15]. However, in the Russian Federation, this method has not received its application due to the need and complexity of creating an information-intensive system of statistical reporting on an alternative energy supply option [5,8]. Also, the Wagner method, physical and exergetic methods contradict the logical requirement to have specific indicators lower for the combined method of producing electric and thermal energy than for their separate production.

The ORGRES method, currently used by the generating companies of the Russian Federation, was developed and introduced on February 1, 1996. The need to develop a new method was that the used of the physical method in calculating the tariff for electricity and heat in market conditions led to an absurd situation: Thermal power plants proved to be uncompetitive in the heat market, industrial enterprises and the population began to refuse to buy heat from thermal power plants en masse and build their own boiler houses and heat generating units. Accordingly, to correct this situation, everyone recognized the need to increase the share of costs associated with the CHPP for electricity production (and thereby reduce the cost of heat), and on the other hand, this process should not lead to a sharp redistribution of fuel costs in favor of heat, as when using the exergetic method. In this regard, the method proposed by ORGRES was adopted for use as a transition from physical to more advanced [5]. Its implementation has had a positive impact on the development of heating and the overall increase in the efficiency of the Russian energy sector. However, the main and significant drawback of this method is that it was adopted as a basic one rather for political reasons, in order to stop the mass refusal of consumers from centralized heat supply from thermal power plants and the transition to individual heat supply from their own boiler houses, which, as a result, leads to an artificial, predetermined and inflexible distribution of the resulting effect from cogeneration in the proportion of about $20 \%$ for thermal energy and about $80 \%$ for electric energy [9, 14], and for some modes, the allocation of electric energy costs by the ORGRES method is more than when using the exergetic method [5].

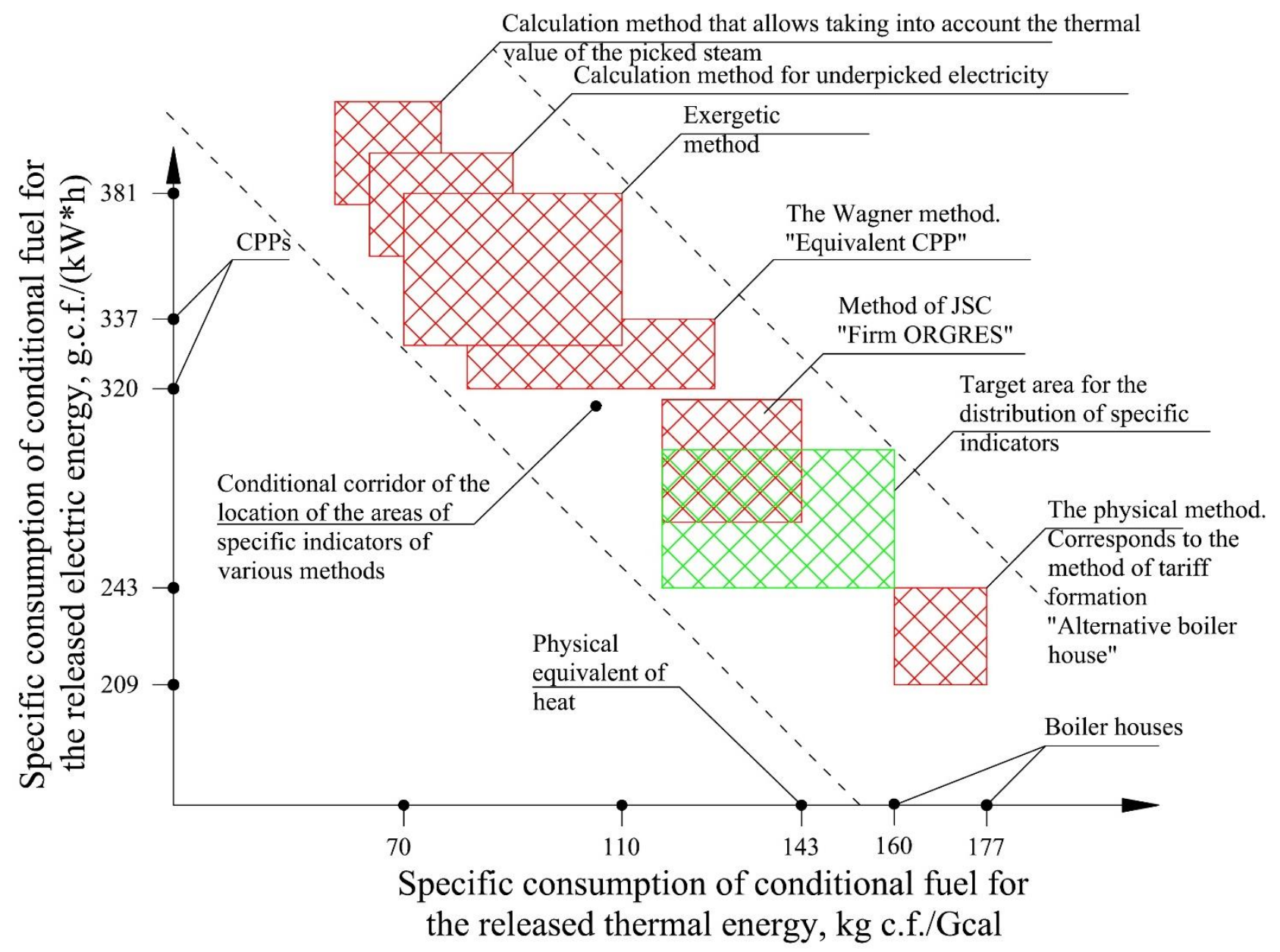

Fig. 1. Graph of the approximate distribution of the areas of specific indicators of known methods (highlighted in red) and the desired target area (highlighted in green) 
Thus, the known alternative methods also have their drawbacks and are not fully acceptable to replace the official methods.

\section{The SFU method}

In such a situation, it is an extremely interesting task to find or develop a new method that is designed to eliminate the shortcomings of existing official and alternative methods and is a compromise option for the entire professional community. To solve this problem, the results of calculations of known methods were analyzed (Fig. 1) [7-9].

As can be seen from the figure, the linear dependence of the specific indicators on each other leads to the distribution of the areas of the known methods according to a linear law in a kind of conditional corridor and, accordingly, finding the desired target area is possible only within the boundaries of this corridor.

All known methods are characterized by a abrupt transition of the region of specific parameters in the case of separate energy production to the region in the case of combined production. Accordingly, this gap is maximal for the exergetic method, and minimal for the ORGRES method.

The target distribution area does not allow for a gap in specific indicators during the transition from separate energy production to combined production, which reflects the logic of a smooth change in the operation mode of the CHPP, rather than a abrupt one. Thus, minimal changes in the operating mode of the CHPP have a minimal impact on the change in specific indicators and vice versa, respectively.

The Siberian Federal University has developed a new method (hereinafter referred to as the SFU method), which eliminates the shortcomings of the known methods and its results are in the identified target area. Currently, the SFU method is being tested on models of real thermal power plants [16].

The target area, in relation to the areas of known methods, provides an optimal distribution of specific indicators and can be a compromise option for observing the economic interests of all participants (generating companies, consumers of electric and thermal energy, regulatory authorities, etc.) [1-4, 10, 14-17].

\subsection{The SWOT analysis}

In part, this conclusion is confirmed by the results of the SWOT analysis of the considered methods for assessing influence the specific characteristics on the socio-economic indicators of the industry. The analysis was based on a number of internal and external factors that determine the effectiveness of the approach, in particular, the internal factors were attributed to: compliance with the physical and logical requirements of the production of electric and thermal energy in the combined cycle; technical and economic feasibility; reduction of specific indicators for both the production of heat and electric energy in the development of heating;

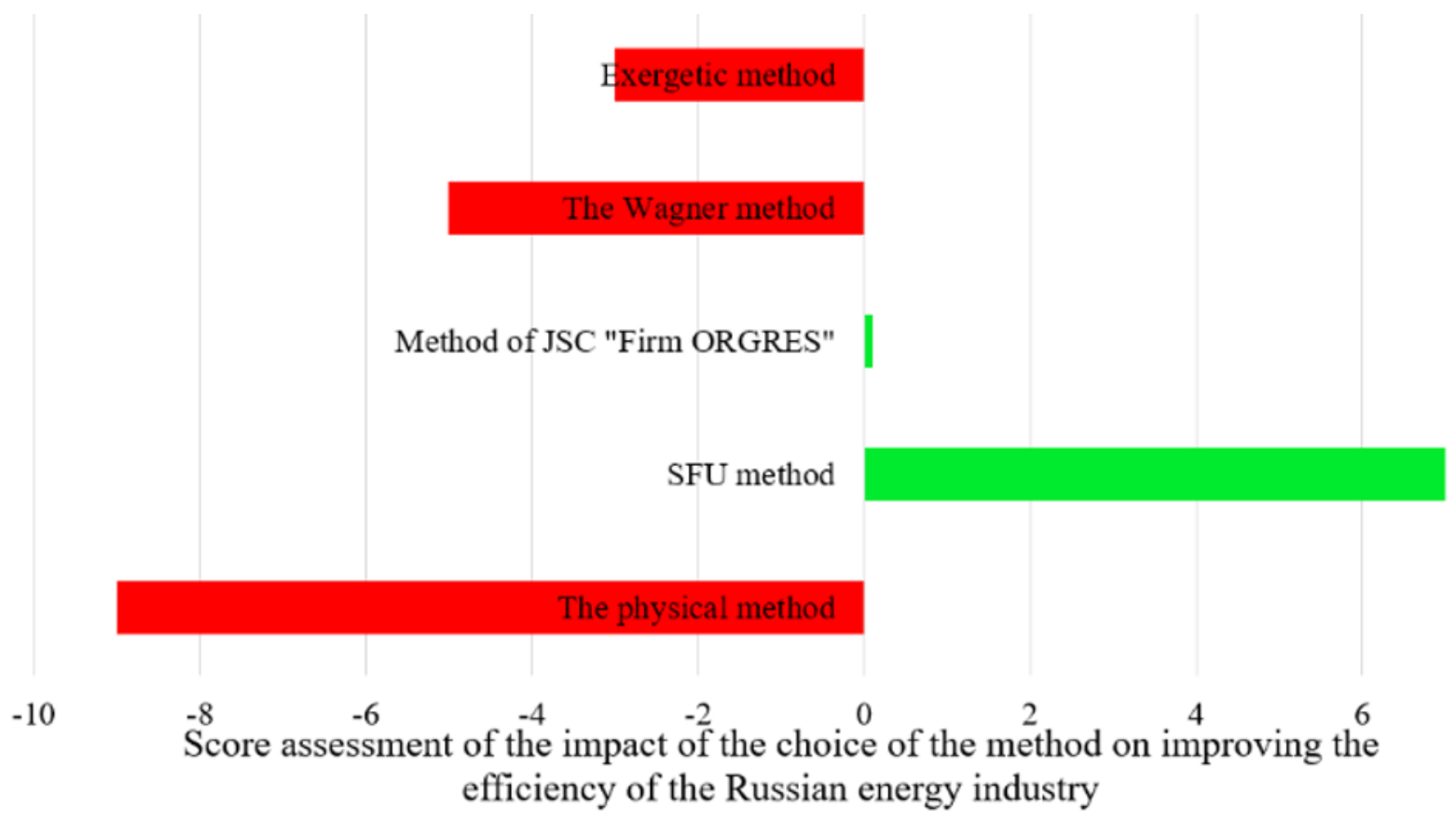

Fig. 2. Results of the SWOT analysis of comparison of various methods for estimating the specific fuel consumption for the production of electric and thermal energy in combined cycle

external factors include: creating conditions for the development of central heating; creating conditions for strengthening the competitive advantages of thermal power plants in the heat and electricity markets; creating conditions for the investment attractiveness of modernization, reconstruction of existing and 
construction of new energy-efficient power plants; respecting the economic interests of all participants (consumers of electric and thermal energy, generating companies, regulatory authorities, etc.). The results of the SWOT analysis are shown in Figure 2.

The results of the SWOT analysis show that the use of the exergetic method, the Wagner method and the physical method is not able to meet the requirements of the socio-economic development of the industry, in fact, as well as the ORGRES method, which once again proves its inefficiency, low objectivity and political orientation. The best indicators of SWOT analysis are provided by the SFU method of estimating specific characteristics in the combined generation of electric and thermal energy.

For the development of the SFU method, the main basic schemes of heat and electric energy generation were considered, the characterizing specific indicators and their mutual location relative to each other (Fig. 3).

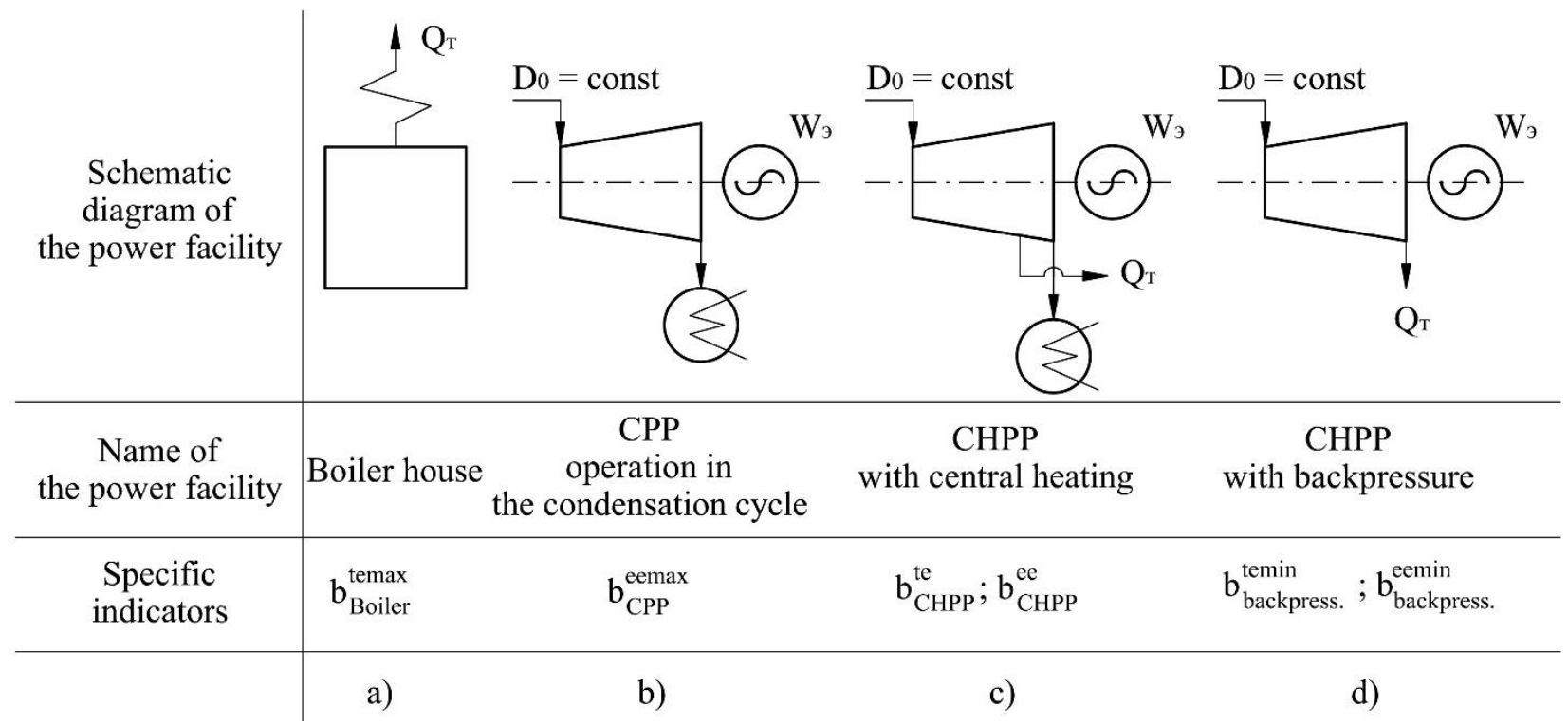

Fig. 3. Basic schematic diagrams of heat and electric energy generation (a) heat energy generation at the boiler house (b) pure condensation electricity generation at the CPP (c) combined heat and electric energy generation at the CHPP in the central heating mode (d) combined heat and electric energy generation at the CHPP in the backpressure mode

\subsection{Formulation}

The obtained effect of SWOT analysis, when using the SFU method, is achieved by the fact that 2 limit modes of operation of the CHPP are fixed (Fig. 4): the least efficient, characterized by separate generation of electric and thermal energy and having the maximum values of the specific indicators of $b_{C P P}^{e e m a x}$ and $b_{B \text { toiler }}^{\text {temax }}$, respectively, and the most efficient, characterized by the operation of the CHPP in the central heating mode at the maximum thermal power of $Q_{C H P P}^{t e}$ and the corresponding electric power of $W_{C H P P}^{t e}$ and having the minimum values of the specific indicators of $b_{C H P P}^{e e m i n}$ and $b_{C H P P}^{\text {temin }}$ accordingly. It also shows the operation mode of the CHPP with backpressure, at the maximum thermal power of $Q_{\text {backpress. }}^{\text {te }}$ and the corresponding electrical power of $W_{\text {backpress. }}^{\text {te }}$ and having the lowest values of the specific indicators of $b_{\text {backpress. }}^{\text {eemin }}$ and $b_{\text {backpress. }}^{\text {temin }}$ accordingly.

The intermediate values of specific indicators within the ranges $" b_{C H P P}^{\text {eemin }}-b_{C P P}^{\text {eemax }}$ " and $" b_{C H P P}^{\text {temin }}-b_{B \text { oiler }}^{\text {temax }}$ correspond to the partial loads of the CHPP and are located inside the area highlighted in green. Part of the electrical energy generated in the condensation cycle is highlighted in the red area and characterizes the addition to the specific indicator for electrical energy.

Recent developments, such as the rejection of the ORGRES method, the return to the physical method, the introduction of the "Alternative Boiler House" tariff setting method [2] leads to the formation of overestimated specific fuel consumption for thermal energy, which, as a result, leads to an overestimation of the cost of production and, accordingly, the tariff for thermal energy, which, in turn, leads to a violation of the economic interests of the main group of consumers - the population $[14,15,18]$.

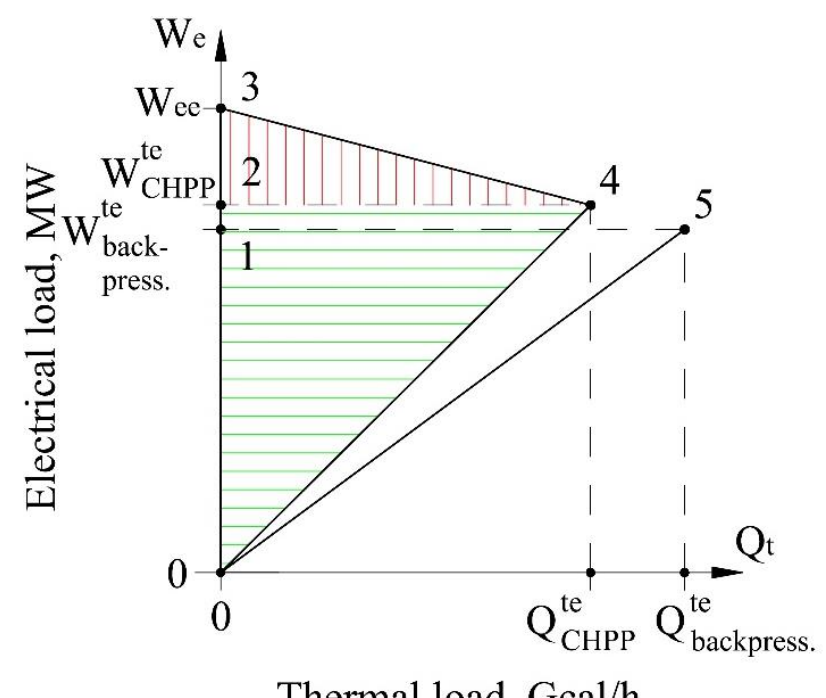

Thermal load, Gcal/h

Fig. 4. Diagram of the distribution of electrical and thermal loads in the combined production of electrical and thermal energy 
At the same time, the reduction in the tariff for electric energy satisfies only such a consumer as industry, since for the population this reduction does not compensate for the increase in the cost of thermal energy. So, in the structure of the utility payment for the population, the cost of heating and hot water is up to $40 \%$, and electricity is up to $20 \%$, with a proportional decrease in the cost of electricity and an increase in the cost of heat, the total utility payment for the population will be higher [4]. And of course it is necessary to take into account the fact that the tools for regulating the consumption and payment of electric energy are available to the population (this is tariff differentiation and the availability of various energy efficiency classes of household equipment on the market, etc.), but the consumption of thermal energy for heating is almost impossible to regulate, since the cost of the service is tied to the area of the room $\left(\mathrm{m}^{2}\right.$ is taken into account). And in this situation, it is possible that the choice of the method can still act as a tool that will allow to regulate the payment for thermal energy by consumers.

Thus, all the technical, thermodynamic, and economic grounds for searching for and replacing the existing methods for estimating specific indicators of fuel consumption for the production of electric and thermal energy in combined cycle have been created for a long time.

Since the physical method is in the extreme position of the distribution area of specific indicators (Fig. 1) and has the minimum specific indicators for the production of electric energy, respectively, the introduction of the SFU method, with combined energy production, will lead to a redistribution of the fuel component in the tariff in the direction of increasing fuel costs for electricity generation, which, accordingly, will lead to an increase in the cost of $\mathrm{kW}^{*} \mathrm{~h}$ and, accordingly, a decrease in fuel costs for the production of thermal energy, which will lead to a decrease in the cost of Gcal $[17,19]$. In the future, the reduction of the tariff for thermal energy in combined generation will increase the economic efficiency of central heating, which will lead to a more active replacement of boiler houses and the new construction of power facilities with combined energy production [20]. On the other hand, it can be seen that the replacement of the ORGRES method will lead to a decrease in the specific indicator of fuel costs for electricity generation, due to a wider range of specific indicators of fuel costs for heat generation. This will increase competition in the heat market and, accordingly, improve the opportunities for CHPPs to compete in the electricity and capacity market.

\subsection{Mathematical calculations}

Creation of the SFU method for estimating the specific indicators that ensure the achievement of the target function (see Fig. 1) it is carried out based on the following logic. From the graph (Fig. 4), we fix $b_{C H P P}^{\text {temin }}$ as the minimum value according to the logical condition that the operation of the CHPP in the central heating mode at the maximum thermal power of $Q_{C H P P}^{t e}$ and the corresponding electrical power of $W_{C H P P}^{t e}$ is the most efficient mode and make the ratio:

$$
\frac{b_{\text {Boiler }}^{\text {te }}}{b_{C H P P}^{\text {temin }}}=\frac{h_{0}}{h_{m}}
$$

Equation (1) reflects the dependence that the closer the steam selection is made to the steam start of the turbine and the enthalpy in the heat selection $\mathrm{h}_{\mathrm{m}}$ tends to the enthalpy of the hot steam $\mathrm{h}_{0}$, the closer the parameter $b_{C H P P}^{\text {temin }}$ to $b_{\text {Boiler }}^{\text {temax }}$ and in the limit when $\mathrm{h}_{\mathrm{m}}=\mathrm{h}_{0}$, which characterizes the physical stop of the steam turbine, and the CHPP operates in the boiler room mode, when the steam from the boiler through the RCU (Reduction cooling unit) is sent to the network heaters, in this case $b_{C H P P}^{\text {temin }}=b_{\text {Boiler }}^{\text {temax }}$, and respectively, the further away from the steam inlet of the turbine and closer to the condenser the steam extraction is performed, the $b_{C H P P}^{t e m i n}$ tends to its minimum value. Accordingly, this encourages the extraction of steam at the lowest steam parameters, increasing the initial steam parameters, since this will eventually lead to lower specific indicators for both thermal and electrical energy.

Thus, it turns out that the width of the range $" b_{C H P P}^{\text {temin }}$ $b_{\text {Boiler }}^{\text {temax }}$ "depends on the initial parameters of the steam and the point of steam extraction, further the range absolute and specific indicators for the production of electric energy is formed and the distribution of specific indicators formed by depending on the mode (specified load) within these ranges.

Fuel consumption for electric power generation,

$$
\mathrm{Bee}=\mathrm{B}-b_{C H P P}^{t e m i n} * Q_{C H P P}^{t e}
$$

where $\mathrm{B}$ is the total fuel consumption, $\mathrm{kg}$

Further, to calculate the specific indicators for different modes of operation of the CHPP, the following data are required: $\mathrm{W}_{\mathrm{LOAD}}$ - electric power at a given load, MW; QLOAD - heating power at a given load, Gcal; B LOAD - total fuel consumption at a given load, $\mathrm{kg}$.

Specific indicator consumption of conditional fuel for thermal energy at a given load, $\mathrm{kg} / \mathrm{Gcal}$

$$
b_{L O A D}^{t e}=b_{\text {Boiler }}^{t e}-\frac{Q_{L O A D}}{Q_{C H P P}^{t e}}\left(b_{\text {Boiler }}^{t e}-b_{C H P P}^{t e}\right)-\frac{\left(\left(b_{\text {Boiler }}^{t e}-\frac{Q_{L O A D}^{t e}}{Q_{C H P P}^{t e}}\left(b_{B o i l e r}^{t e}-b_{C H P P}^{t e}\right)\right)-b_{C H P P}^{t e}\right) * \frac{w_{C H P P}^{t e}}{Q_{C H P P}^{t e}}}{\frac{W_{L O A D}}{Q_{L O A D}}}
$$

fuel consumption for heat generation at a given load, $\mathrm{kg}$

$$
B_{L O A D}^{t e}=b_{L O A D}^{t e} * \mathrm{Q}_{\mathrm{LOAD}}
$$

fuel consumption for the generation of electrical energy at a given load, $\mathrm{kg}$

$$
B_{L O A D}^{e e}=B_{L O A D}-B_{L O A D}^{t e}
$$

Specific indicator consumption of conditional fuel for 
electrical energy at a given load, $\mathrm{kg} /\left(\mathrm{kW}^{*} \mathrm{~h}\right)$

$$
b_{L O A D}^{e e}=\frac{B_{L O A D}^{e e}}{W_{L O A D}}
$$

\subsection{Approbation}

To calculate the feasibility and efficiency of the SFU method for estimating specific indicators fuel consumption in the combined generation of electric and thermal energy, an analytical experiment was performed in relation to the evaluation of the performance indicators of the turbine units PT-25-90/13, PT-60-90/13, BP-858,8, BP-100-130 of the Krasnoyarsk CHPP-1, T-100-130 and PT-135/165-130/13 of the Krasnoyarsk CHPP-2, T185-130 of the Krasnoyarsk CHPP-3 and PT-80-130/13 Minusinskaya CHPP [21].

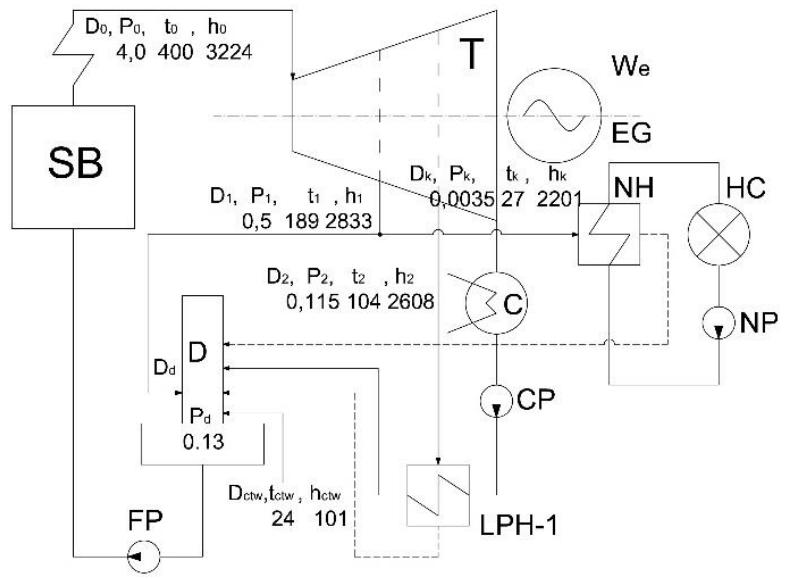

Fig. 5. The principle thermal scheme of the CHPP: We = 8 MW; Qte $=30$ Gcal

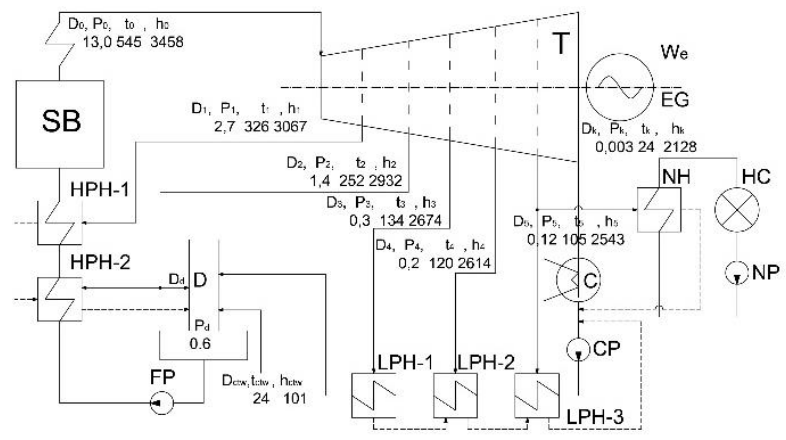

Fig. 6a. The principle thermal scheme of the CHPP: $\mathrm{We}=80 \mathrm{MW} ;$ Qte $=100 \mathrm{Gcal} ; \mathrm{h}_{\mathrm{m}}=2543 \mathrm{~kJ} / \mathrm{kg}$

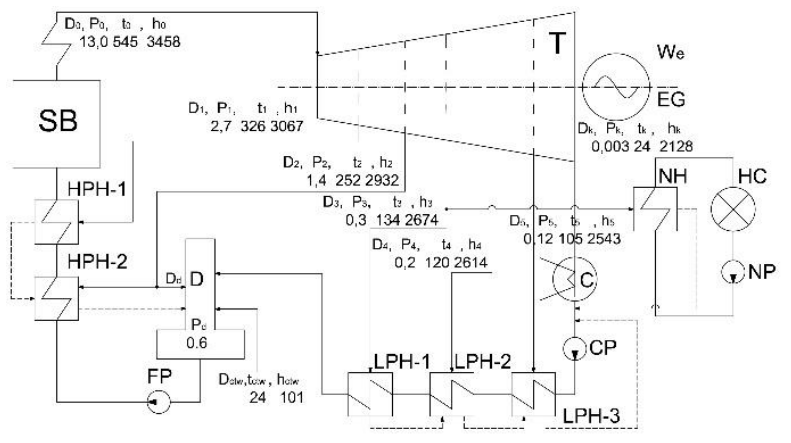

Fig. 6b. The principle thermal scheme of the CHPP: $\mathrm{We}=80 \mathrm{MW} ;$ Qte $=100 \mathrm{Gcal} ; \mathrm{h}_{\mathrm{m}}=2674 \mathrm{~kJ} / \mathrm{kg}$
A number of examples of calculated thermal schemes are presented in Fig. 5 and 6.

A comparative analysis of the calculated data obtained for all the thermal schemes presented above shows that for the 8 MW CHPP scheme, due to lower initial steam parameters, as well as due to a higher value of the enthalpy of the selection steam used for heating purposes, the specific fuel consumption indicators were significantly higher than for the $80 \mathrm{MW}$ CHPP thermal schemes, so for the specific fuel consumption indicators for thermal energy, the values were $141-161 \mathrm{~kg}$ c.f./Gcal (Fig. 7a) versus 118 - $161 \mathrm{~kg}$ c.f./Gcal (Fig. 8a), $124-$ $161 \mathrm{~kg}$ c.f./Gcal (Fig. 9a), for specific indicators of fuel consumption for electric energy, the values were 268-402 g c.f./(kW*h) (Fig. 7a) against $276-357$ g c.f./(kW*h) (Fig. 8a), $287-357$ g c.f./(kW*h) (Fig. 9a).

Thus, the application of the SFU method reflects the feasibility of increasing the initial parameters of steam to reduce the specific indicators fuel consumption.

For the 80 MW CHPP scheme with the steam enthalpy in the selection $h_{m}=2543 \mathrm{~kJ} / \mathrm{kg}$, the specific fuel consumption indicators were lower than for the $80 \mathrm{MW}$ CHPP scheme with the steam enthalpy in the selection $\mathrm{h}_{\mathrm{m}}$ $=2674 \mathrm{~kJ} / \mathrm{kg}$ and amounted to $118-161 \mathrm{~kg}$ c.f. $/$ Gcal (Fig. 8a), for the specific fuel consumption indicators for thermal energy against 124 - $161 \mathrm{~kg}$ c.f./Gcal (Fig. 9a), and, accordingly, the specific fuel consumption indicators for electrical energy $276-357$ g c.f./(kW*h) (Fig. 8a) vs. $287-357$ g c.f./(kW*h) (Fig. 9a).

In this regard, the use of the SFU method explains the efficiency of steam extraction at lower parameters to reduce specific fuel consumption indicators.

The results of the calculation by the SFU method, in relation to various typical schemes of thermal power plants (Fig. 5, 6a, 6b), exactly fall into the target area of the distribution of specific indicators (Fig. 1, 7, 8, 9). It is shown that with an increase in the heat load, an increase in the nominal parameters of steam, a decrease in the parameters of selected steam, the specific indicators for both electric and thermal energy decrease, which improves the competitive advantages of thermal power plants in the markets of thermal and electric energy and capacity, as well as creates conditions for competition between different thermal power plants, promotes the development of central heating.

The results of the calculation according to the 4 known methods (Fig. 7, 8, 9), tested on the schemes of the CHPP of the Siberian Generating Company LLC (Fig. 5, 6a, 6b), show a linear dependence of the specific indicators from each other and are located along the conditional corridor, in accordance with the data (Fig. 1). At the same time, the results of the calculation by the SFU method exactly fall into the target area of the distribution of specific indicators (Fig. 1, 7, 8, 9). In fig. 7b the specific indicators for electric energy obtained by the calculation using the ORGRES method turned out to be significantly higher than when calculating using the exergetic method, which clearly demonstrates the manifestation of one of the disadvantages of the ORGRES method [5]. 


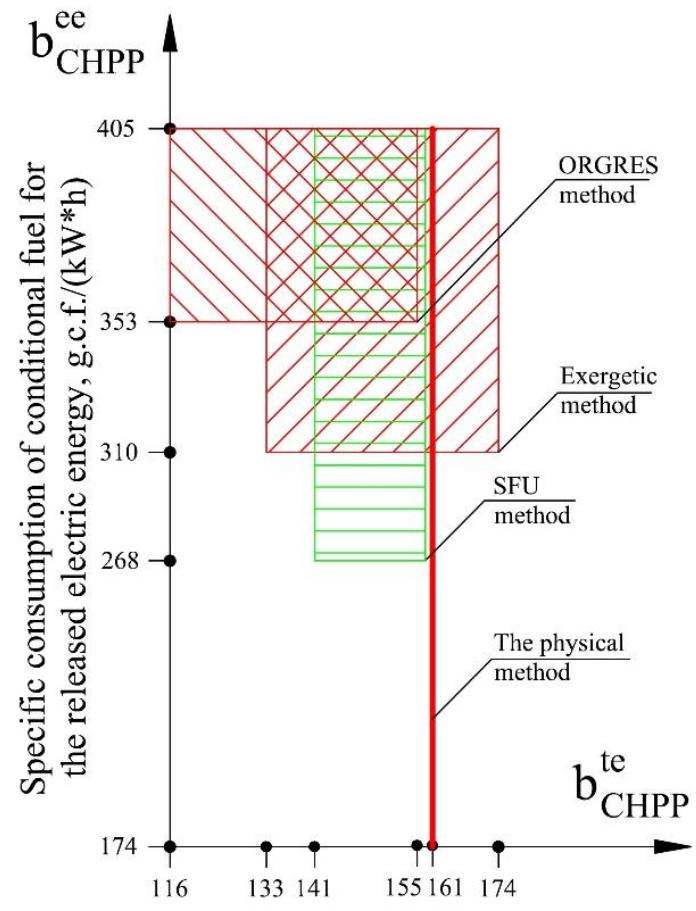

Specific consumption of conditional fuel for the released thermal energy, $\mathrm{kg}$ c.f./Gcal

a)

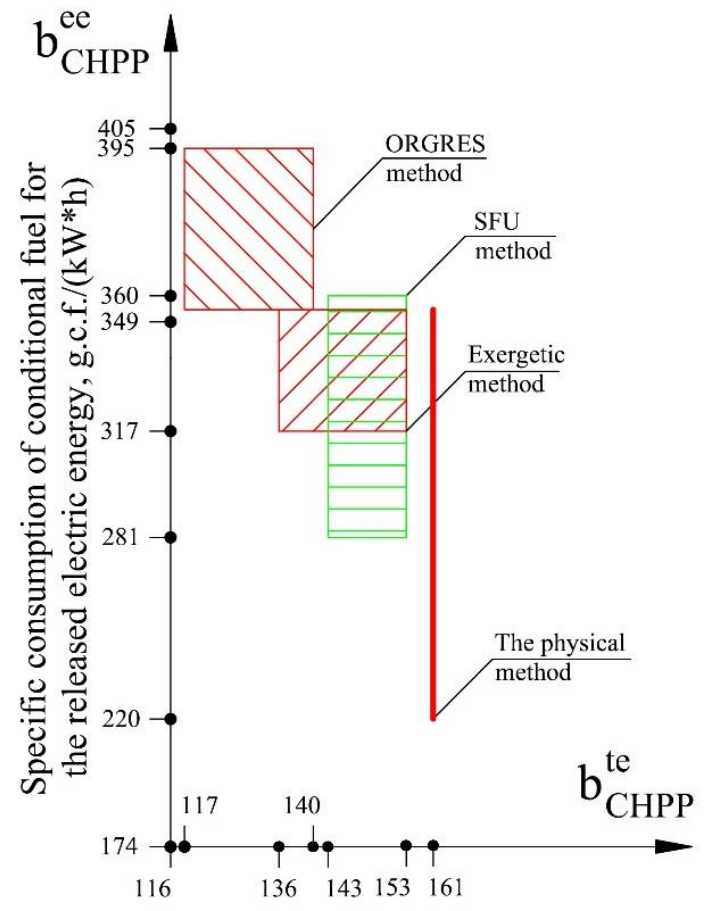

Specific consumption of conditional fuel for the released thermal energy, $\mathrm{kg}$ c.f./Gcal

b)

Fig. 7. Graphs of the distribution of specific indicators for CHPP We $=8 \mathrm{MW}$ : taking into account the limit modes (minimum and maximum loads) (a); without taking into account the limit modes (b)

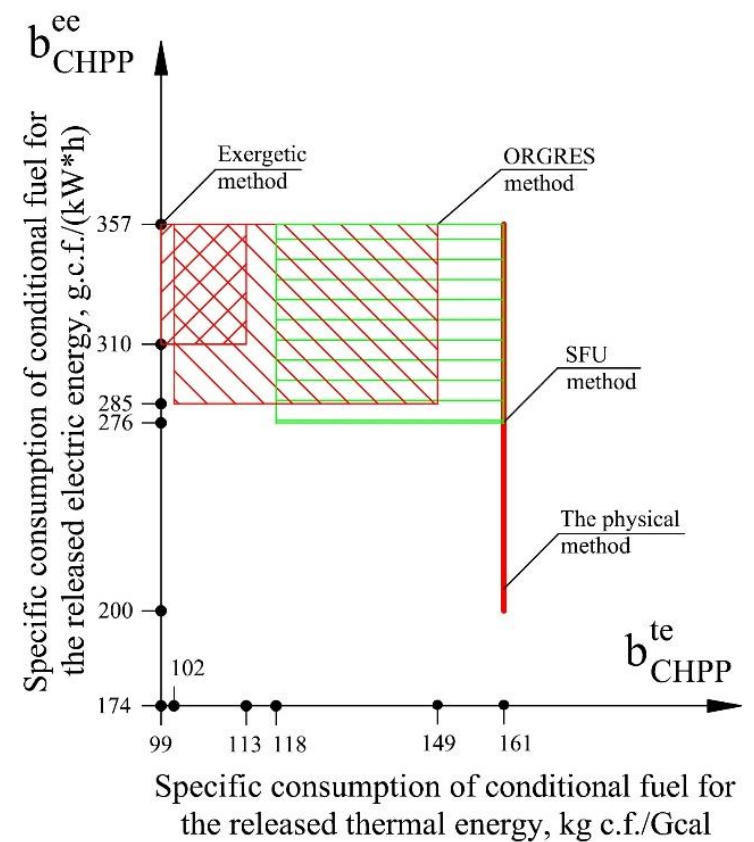

a)

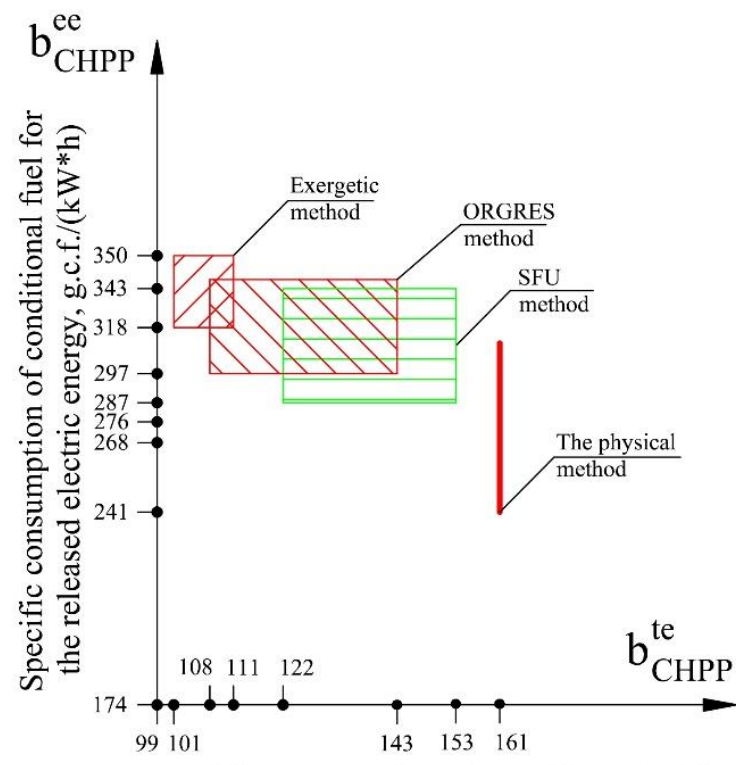

Specific consumption of conditional fuel for the released thermal energy, $\mathrm{kg}$ c.f./Gcal

b)

Fig. 8. Graphs of the distribution of specific indicators for CHPP We $=80 \mathrm{MW}$ with selection $\mathrm{h}_{\mathrm{m}}=2543 \mathrm{~kJ} / \mathrm{kg}$ : taking into account the limit modes (minimum and maximum loads) (a); without taking into account the limit modes (b) 


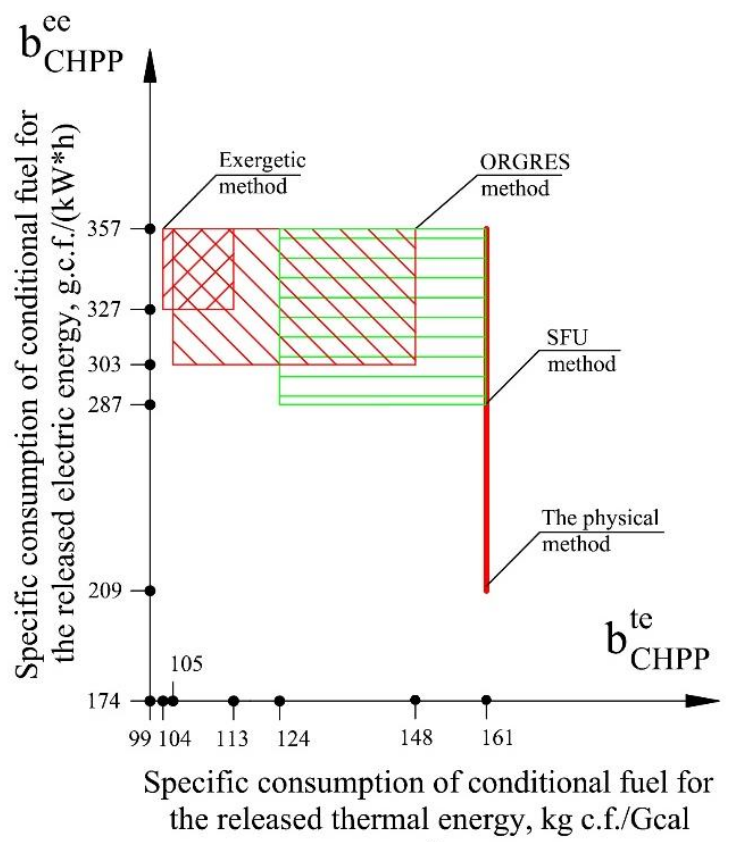

a)

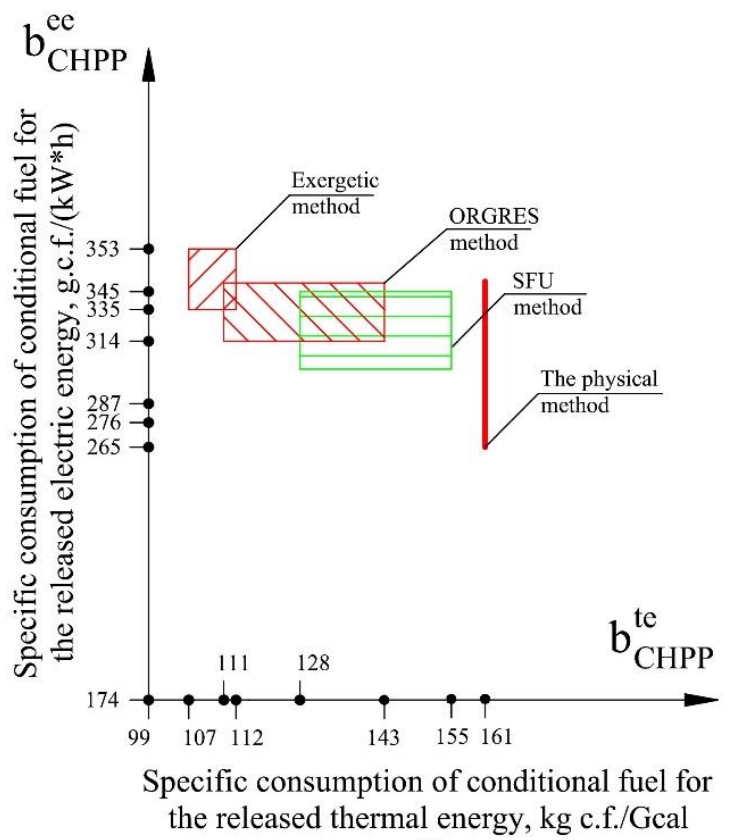

b)

Fig. 9. Graphs of the distribution of specific indicators for CHPP We $=80 \mathrm{MW}$ with selection $\mathrm{h}_{\mathrm{m}}=2674 \mathrm{~kJ} / \mathrm{kg}$ : taking into account the limit modes (minimum and maximum loads) (a); without taking into account the limit modes (b)

\subsection{Impact on tariffs}

Of particular interest is the extrapolation and comparative comparison with alternative methods of the proposed method for calculating specific characteristics in the combined production of electric and thermal energy for the size of the calculated tariff (see Table 1).

According to the results of the comparative analysis presented in Table 1 it can be seen that the average calculated indicators of specific fuel consumption for thermal energy when using the proposed SFU method, relative to the physical method, are $20 \%$ lower. The lack of consideration of this fuel economy effect in the production of thermal energy leads to the fact that the tariff for thermal energy based on the physical method, which is the basis of the "Alternative Boiler House" approach, is overstated by $10-15 \%$.

Table 1. Influence of the method choice on the formation of the heat energy tariff

\begin{tabular}{|l|c|c|c|c|c|}
\hline $\begin{array}{c}\text { Name of the } \\
\text { method }\end{array}$ & $\begin{array}{c}\text { Average calculated } \\
\text { indicator of specific } \\
\text { fuel consumption } \\
\text { for thermal energy, } \\
\text { kg c.f./Gcal }\end{array}$ & $\begin{array}{c}\text { Calculated } \\
\text { tariff, } \\
\text { rub/Gcal }\end{array}$ & $\begin{array}{c}\text { Calculated } \\
\text { reduction in } \\
\text { the cost of } \\
\text { thermal } \\
\text { energy, } \%\end{array}$ & $\begin{array}{c}\text { Average calculated } \\
\text { indicator of specific } \\
\text { fuel consumption for } \\
\text { electric energy, } \\
\text { g c.f./(kW*h) }\end{array}$ & $\begin{array}{c}\text { Calculated cost of } \\
\text { electricity production } \\
\text { at a CHPP, } \\
\text { rub/(kW*h) }\end{array}$ \\
\hline Exergetic & 106,5 & $1600-1750$ & $20-25$ & 334 & 322 \\
\hline ORGRES & 125,5 & $1750-1900$ & $15-20$ & 315 & $0,75-0,77$ \\
\hline SFU & 139,5 & $1900-2000$ & $10-15$ & 292 & $0,74-0,75$ \\
\hline Physical* & 176,4 & $2200^{* *}$ & - & $0,73-0,74$ \\
\hline
\end{tabular}

* - according to the Ministry of Energy, the calculator for calculating the cost of thermal energy (capacity) using the "alternative boiler house" method (ABH method), http://instrument-ak.minenergo.gov.ru, initial data is the Krasnoyarsk Territory, fuel coal; ** - average tariff for the settlements of the Krasnoyarsk Territory. 
Thus, the use of the proposed SFU method for calculating specific characteristics for combined generation of electric and thermal energy can be considered a scientifically-based compromise for assessing the long-term tariff, taking into account the interests of all participants in the heating market, including the main group of consumers - the population. At the same time, the increase in the cost of electricity production will be only $0.03-0.04$ rubles/(kWh), which is $4-5 \%$, what for formation of the final tariff of 4-5 rubles/(kW*h) has no practical effect.

The use of the proposed SFU method, as the only official one, will allow for the correct comparative technical and economic modeling of energy supply options for consumers, taking into account the long-term development, and the definition of tariff rules based on the decisions made on the selected option will create the necessary long-term conditions for the investment attractiveness of modernization, reconstruction of existing and construction of new energy-efficient power plants, which will fully meet the economic interests of consumers, and generating companies. Meeting the economic interests of all participants in the heating market is one of the main components in solving the strategic task of improving the energy efficiency of the industry.

\section{Conclusions}

1. The paper shows the imperfection of the existing methods for assessing specific indicators in the combined production of electric and thermal energy (exergetic, physical, ORGRES method), which leads to the emergence of objective contradictions between the participants of the heating market, manifested in noncompliance with economic interests in terms of reducing specific fuel consumption, creating conditions of investment attractiveness for the modernization, reconstruction of existing and construction of new energy-efficient sources of energy supply.

2. Based on the calculated and comparative analysis of existing methods for assessing specific characteristics, the target range of values is determined, the achievement of which ensures an optimal distribution of specific performance indicators of the CHPP, which is a compromise for all participants in the central heating market.

3. The SFU method is proposed, based on logical requirements, matching the degree of change in the operation mode of the CHPP to the degree of change in specific indicators, obtaining specific characteristics in the combined production of electric and thermal energy lower than in their separate production, reducing the specific indicators for heat and electric energy with an increase in the heat load, increasing the initial steam parameters, using selected steam with lower parameters, and also devoid of the disadvantages of known methods, primarily the method of JSC "Firm "ORGRES" and the physical method.

4. The use of the proposed SFU method for estimating specific characteristics in the combined production of electric and thermal energy allows for a $10-15 \%$ reduction in the tariff for thermal energy relative to the physical method "Alternative boiler House" , with an increase in the cost of production of electric energy by $4-5 \%$, which practically does not affect the formation of the final tariff for electric energy and provides a cumulative effect on the economic attractiveness and development of the energy industry as a whole.

\section{References}

1. G.Y. Vagin, Industrial power engineering, 5, 2-6 (2013)

2. A.B. Bogdanov, Thermal energy, 03(12), 6-9 (2014)

3. S.S. Beloborodov, Energosovet, 3(40), 24-28 (2015)

4. A.B. Bogdanov, P.F. Abdushukurov, Thermal energy, 05(14), 6-7 (2014)

5. E.V. Sukhareva, Transport business of Russia, 2, 43$45(2015)$

6. V.M. Brodyansky, V. Fratsher, K. Mikhalek, Exergetic method and its applications (Energoatomizdat, 1988)

7. G.P. Kiselev, Options for calculating the specific performance indicators of the CHPP: textbook (MPEI Publishing House, 2003)

8. N.A. Slavina, E.M. Kosmatov, E.E. Barykin, Electric power stations, 11, 14-17 (2001)

9. D.M. Suvorov, Scientific researches and their practical application. Modern state and ways of development, 1-10 (2012)

10. A.B. Bogdanov, O.A. Bogdanova, Heat and energy efficient technologies, 1, 6-31 (2013)

11. Maciej Sołtysik, Karolina Mucha-Kuś, Acta Energetica, 3/20, 134-139 (2014)

12. Maciej M. Sokołowski, European Law on Combined Heat and Power (Routledge, 2020)

13. A Stoltmann, M Jaskólski, P Bućko, IOP Conf. Series: Earth and Environmental Science 214 (2019) 012036, 1-10 (2019)

14. A.B. Bogdanov, O.A. Bogdanova, Plumbing, Heating, Air Conditioning, 1, 96-104 (2017)

15.E.V. Sukhareva, M.V. Kahalnikov, Economic sciences, 4(173), 108-111 (2019)

16. E.A. Boiko, D.G. Didichin, P.V. Shishmarev, Mathematical modeling of heat and power problems on a computer: Guidelines for laboratory work for students of specialties 1005 - "Thermal power plants", 1007 - "Industrial heat and power engineering" (KGTU, Krasnoyarsk, 2001)

17. V.S. Stepanov, T.B. Stepanova, N.V. Starikova, Industrial power engineering, 3, 2-7 (2016)

18. B.V. Yakovlev, Energy and management, 6, 38-41 (2005)

19. G.Zh. Daykeev, V.D. Ogai, Problems of reforming the electric energy market in Kazakhstan: Collection of tr. based on the materials of the joint scientific and practical seminar, P.I, 49 - 55 (2005)

20. M.V. Kolosov, A.V. Zhuikov, Industrial power engineering, 7, 21-22 (2013)

21. E.A. Boiko, Computer application for solving heat and power problems (Krasnoyarsk, Siberian fishery, 2001). 